\title{
Double alternation in children's binary choice responses'
}

DAVID ROSENHAN

ETS CENTER FOR PSYCHOLOGICAL STUDIES

The presence of significant amounts of double alternation in a 70:30 binary choice problem is demonstrated among first-grade children as a function of positive reinforcement and of instructions that stress only correct responses.

The presence of single (side-to-side) alternation and of relatively stereotyped responses to one lever has been noted frequently in various kinds of learning experiments, and several models exist for understanding these phenomena (Dember \& Fowler, 1958; Skinner, 1942; Tune, 1961). The present experiment indicates the presence of a substantial amount of double alternation in a two-choice probability-learning experiment, resulting from the valence of reinforcement and instructional explicitness. The unanticipated presence of double alternation is of interest both because it has not been previously reported in such learning situations, and because it poses peculiar problems for theories of learning and arousal that attempt to account for behavior in the two-choice situation.

Method

Subjects. Ss were 64 first-grade children, equally divided among boys and girls. A female E conducted the experiment.

Apparatus. S's mechanism was a black box with two toggle automatic-return switches along the lower edge of the front panel. A buzzer located inside S's machine signaled him to make a response which was then transmitted to and recorded from a monitoring device.

Procedure. A 2 by 2 design was implemented in which the valence of reinforcement and explicitness of instructions were varied. In the positive-reinforcement-explicit condition (PRE) $\mathrm{S}$ was told "If you push the right button I'll say 'right.' If I don't say anything, it means that the button you pushed was wrong." For the negativereinforcement-explicit condition (NRE) E said, "If you push the wrong button I'll tell you it's wrong. If I don't say anything, it means that the button you pushed was right." In the implicit conditions, E did not remark on the meaning of nonreinforcement. Thus, for the positive-reinforcement-implicit condition (PRI), E simply said, "If you push the right button I'll say 'right'," while for the negative-reinforcement-implicit (NRI) condition, E said, "If you push the wrong button, I'll say "wrong'," adding no further remarks on the value of the right button. These instructions were rephrased and repeated several times.

Ss were reinforced on each of the 160 trials. Intertrial interval was 2 sec. The reinforcement ratio was $70: 30$, randomly distributed in blocks of 20 trials. For the PRE and PRI conditions, 70 percent of the left-hand responses and 30 percent of the right-hand responses were positively reinforced. For the NRE and NRI conditions, the reverse inputs were employed. Thus, responses to the left lever were correct more often for all experimental conditions.

\section{Resulis}

Choice Preference. The mean left lever responses over all trials ranged from 56 percent to 60 percent; for trials $101-160$, it ranged from 58 percent to 62 percent. Analysis of variance indicated no differences in left lever responding as a function of either experimental condition $(\mathbf{F}<2)$.

Response Patterns. In order for a response to qualify as either a single alternation ( $A B A B A$ or $B A B A B$ ), double alternation (AABBAA or $B B A A B B$ ), or stereotyped response (AAAAA or $B B B B B$ ), it had to be preceded by four similar responses. The probabilities of such response sequences occurring were sufficiently low that one could safely term them patterns or strategies. A response was scored in one and only one category.

Three nonredundant scores were thus obtained: single alternation, double alternation, and perseveration. Close to 90 percent of the total responses consisted of some kind of patterned response to the task. Similar findings with regard to patterning have been reported by others (Gerjuoy \& Gerjuoy, 1965; Tune, 1964).

Each pattern was subjected to a 2 by 2 analysis of variance. For single alternation and perseveration the analyses were computed on arcsin transformed data, and no effects were found (all Fs $<2.00$ ). Both valence of reinforcement $(F=4.10 ; p<.05)$ and instructional explicitness $(F=6.28 ; p<.01)$ affected the degree to which double alternation was present. As Fig. 1 indicates, the level of double alternation in the implicit instructions condition was consistent and high throughout all trials.

\section{Discussion}

The presence of double alternation responses constitutes something of a dilemma for various learning theories, since from these theories one would expect a tendency to repeat the reinforced response. This dilemma has, of course, been confronted previously in the context of single alternation (cf. Dember \& Fowler, 1958; Tune, 1964). Consider Hull's (1943) reactive inhibition hypothesis. The tendency to respond to the left is presumed to be inhibited immediately after a left response, rendering a right response momentarily predominant. In the case of double alternation, however, 


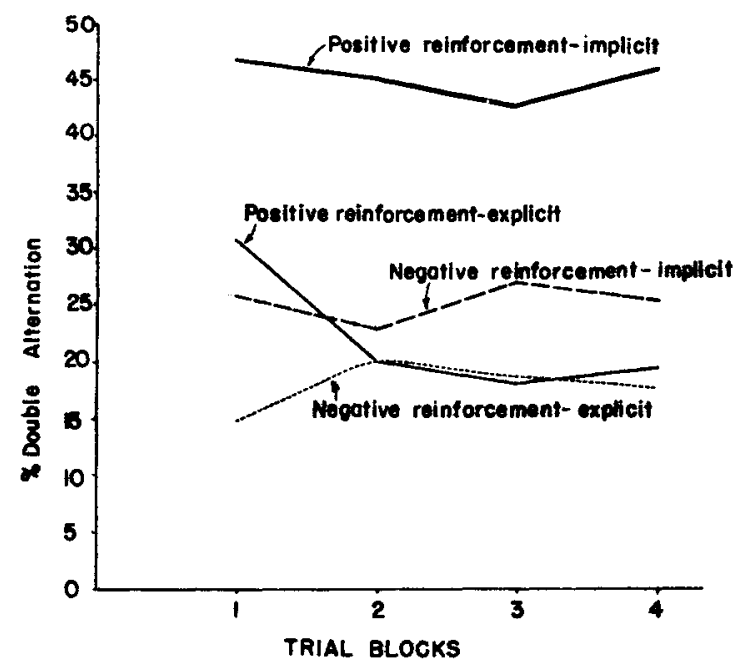

Fig. 1. Double alternation in blocks of 40 trials as a function of experimental condition.

the right response gains ascendency only after two left responses, a phenomenon that cannot be accounted for by $I_{r}$. Similar arguments hold for Glanzer's (1953) stimulus satiation, Walker's (1956) action decrement, and Jarvik's (1951) negative recency effects. Skinner's (1942) notion that response alternations reflect subjective perceptions of chance may be applicable here, but they do not directly account for why S's expectations should take this particularly symmetrical form, nor why they should be associated with specific conditions of information and reinforcement under asymmetrical conditions of reinforcement.

We have no ready and supportable explanation of double alternation. We are inclined to believe that double alternation is neither a problem-solving strategy, as these sequential dependencies are often labeled, nor is it associated with learning as such. Our belief is based on the fact that the levels of double alternation remained consistent throughout the experiment, showing none of the acquisition characteristics typically associated with learning. Moreover, we obtained evidence that our Ss learned the correct response even though their choice preferences and response patterns did not directly reflect it. In response to the post-experimental question "Which was the best button?"' all but two of the 64 Ss pointed to the left lever (and the two who were not certain appeared to manifest no special pattern of responding). Thus, we apparently obtained "awareness without learning."

The failure of this sample to match, let alone maximize, the input probabilities is consistent with findings reported by Kessen \& Kessen (1961) and Weir (1964) for children of this age. However, even among young children, where the incentive value of being praised is high (and being told by an acult $E$ that one's response is right can be interpreted as praise by a young child), matching and even maximizing can occur. Thus, lowerclass children, for whom reinforcers from a middleclass $E$ are presumed to have high incentive value, will match or exceed input probabilities (Rosenhan, in press).

Second, the ineidence of single alternation among these S6 is also noteworthy. Averaging 45 percent of all responses, it is consistent with findings reported previously (Gerjuoy \& Gerjuoy, 1965; Weir, 1964).

\section{References}

Dember, W. D., \& Fowler, H. Spontaneous alternation behavior. Psychol. Bull., 1958, 55, 412-428.

Gerjoy, Ima R., Gerjuoy, H. Binary choice sequences of re tardates, normal children and college students under randomand pattem-set instructions. Amer. J. ment. Defic., 1965, 69, 854-859.

Glanzer, M. Stimulus satiation: An explanation of spontaneous alternation and related phenomena. Psychol. Rev., 1953, 60, 257-268.

Hull, C. L. Principles of behavior. New York: Appleton-CenturyCrofts, 1943.

Jarvik, M. G. Probability learning and negative recency effect in serial anticipation of alternate symbols. J. exp. Psychol., 1951, $41,291-297$.

Kessen, W., \& Kessen, Marion L. Behavior of young children in a two-choice guessing problem. Child Develpm., 1961, 32, 779788 .

Rosenhan, $\mathbf{D}$. The effects of social class and race on responsiveness to approval and disapproval. J. Pers. soc. Psychol., in press.

Skinner, B. F. The processes involved in the repeated guessing of alternatives. J. exp. Psychol., 1942, 30, 495-503.

Tune, G. S. Response preferences: A review of some relevant literature. Psychol. Bull., 1964, 61, 286-302.

Walker, $\mathbf{E}$. L. The duration and course of reaction decrement and the influence of reward. J. comp. physiol. Psychol., 1956, 49, 167-176.

Weir, M. H. Developmental changes in problem solving strategies. Psychol. Rev., 1964, 71, 473-490.

Note

1. This research was supported in part by Public Health Service Grant No. MH-0760-01. Gratitude is expressed to Molly Martin and Jean Greenwald who collected the data. Henrietta Gallagher devised the computer program for eliciting sequential dependencies and analyzed the data. 